\title{
Intonation in Spanish declaratives: differences between lab speech and spontaneous speech ${ }^{*}$
}

\section{Timothy L. Face}

University of Minnesota. Department of Spanish and Portuguese Studies

34 Folwell Hall. 9 Pleasant St. SE. Minneapolis, MN 55455

facex002@umn.edu

\begin{abstract}
The present study compares the intonation of Spanish declarative utterances in lab speech and spontaneous speech. Most studies of Spanish intonation have used lab speech, collected in an experimental setting and often scripted. This allows the researcher to control many factors, but the results cannot be assumed to be representative of spontaneous speech. The present study takes the most characteristic traits of the intonation of declarative sentences in Spanish lab speech and examines whether the same traits exist in spontaneous speech. It is shown that there are notable differences between the intonation of Spanish declaratives in lab speech and spontaneous speech. While some of the differences are minor, others are quite significant. Differences of one degree or another exist in the areas of the presence of F0 rises through stressed syllables, F0 peak alignment, downstepping, final lowering and deaccenting.
\end{abstract}

Key words: intonation, Spanish, pitch, F0, downstepping, final lowering, deaccenting, spontaneous speech, lab speech.

\section{Introduction}

The study of Spanish intonation has a long history, dating back at least to the ground breaking work of Navarro Tomás $(1918,1944)$. While there were many small-scale studies of Spanish intonation following the work of Navarro Tomás, it has not been until recently that the study of Spanish intonation has attracted a community of scholars interested in its various aspects. Recent studies have focused on the phonetic, phonological, pragmatic, and functional aspects of Spanish intonation. While other types of utterances have been examined by a few scholars, the majority of studies on Spanish intonation have been dedicated to declaratives. The result is that the intonation of declarative utterances in Spanish is fairly well understood, at least from a phonetic and phonological perspective. While it is undeniable that

* I would like to thank Mercedes Cabrera Abreu, José Ignacio Hualde, and Pilar Prieto for their very helpful suggestions on an earlier version of this paper that led to significant improvements. Any errors, whether of fact or interpretation, remain my own. 
the wealth of studies on Spanish declaratives has immensely furthered our knowledge of Spanish intonation, there is an important limitation to these studies. Nearly all studies on Spanish intonation have analyzed lab speech, viz. speech elicited in a laboratory or experimental setting, and often scripted, for the purpose of a linguistic study. Lab speech is essential to understanding intonation. There are so many intertwining factors in spontaneous speech that can affect the intonation of an utterance, that it can be impossible to determine at first what factor causes a particular intonational phenomenon. By creating carefully constructed experiments to elicit lab speech, the researcher can control the many variables and determine how each affects the intonation pattern. But while lab speech is invaluable in intonational studies, it cannot be assumed that the intonation patterns produced in lab speech are an accurate representation of the intonation patterns of spontaneous speech. The present study is a preliminary investigation of the differences between the intonation of Spanish declaratives found in lab speech and that found in spontaneous speech.

A full comparison of the intonation patterns of lab speech and spontaneous speech in Spanish - even if limited to declaratives - is not only beyond the scope of the present paper, but is also impossible based on present knowledge. While studies of lab speech have revealed much about Spanish intonation, there is much still to be investigated. And very little is known about the intonation of spontaneous Spanish speech. Therefore the present study is limited to some of the more well-studied aspects of Spanish intonation in lab speech, and examines the same issues in spontaneous speech. This examination is limited to phonetic description, and avoids making any phonological analyses, which would necessarily require adopting certain theoretical assumptions. In this way the present study is a first step toward understanding just a few of the differences that exist between the intonation of Spanish lab and spontaneous speech.

At this point it is worth pointing out that the difference between lab speech and spontaneous speech is not necessarily a categorical one. Rather these two styles sit at opposite ends of a continuum, with other styles falling between these two. One such style is the retelling of a popular story using only pictures to guide the speaker. This elicitation technique has been employed by Grabe (1998) and by Grabe and her colleagues in the English Intonation in the British Isles project (see Farrar, Grabe and Nolan 1999 for a description of the project). The retelling of a story, since it is not reading, should provide a more spontaneous speech style. Another technique used to elicit data more spontaneous than in read lab speech is through a dialogue game. Krahmer and Swerts (2001), for example, use such a game to force the production of phrases containing contrast so that they can investigate whether contrastive accents exist. Another technique, and one perhaps eliciting speech closest to spontaneous speech without being truly spontaneous, is the use of map tasks. In such tasks two subjects each have a map, with one of them having a route drawn on it. The subjects must interact until the second subject has drawn the identical route on the other map. Difficulties are included, such as items on the map appearing in different locations or having different names. Map tasks are used, for example, in the English Intonation in the British Isles project and by Grice and 
Savino (this volume) in investigating the intonation of question types in Bari Italian. Another technique that has been used by at least Hualde (2002) is for a linguist to produce in a laboratory setting an intonation pattern that he can envision a context for in his native language. While this could sound like a contrived way of producing intonation data, it is an efficient way of producing an isolated example or two of an intonation pattern that exists in spontaneous speech without having to have access to a corpus of spontaneous speech data. The present study examines the extreme ends of the continuum of speech styles: lab speech and spontaneous speech. However, these are certainly not the only styles that exist.

The remainder of this paper is laid out as follows: Section 2 presents a discussion of what is known about declarative intonation in Spanish from existing studies of lab speech, with a focus on the aspects to be compared with spontaneous speech in this study. Section 3 discusses the nature of the spontaneous speech data used in the present study. Section 4 presents the results of the investigation of the intonation patterns in spontaneous Spanish declaratives. Section 5 considers the place of the findings of the present study in the ongoing work on Spanish intonation and considers topics for future investigations.

\section{Intonation of Spanish declaratives in lab speech}

Navarro Tomás (1944) makes two important observations about the intonation patterns of Spanish declaratives that have received renewed attention in recent work. These two observations are 1) that in the body of the fundamental frequency (F0) contour (i.e. that which precedes the final stressed syllable of the utterance) the F0 rises throughout stressed syllables, and 2) that the F0 often reaches its highest point in the post-tonic syllable. The fact that the F0 reaches its highest point in a post-tonic syllable has led to a debate as to the correct phonological analysis of the pitch accent responsible for this F0 rise (e.g. Face 1999, 2001b, 2002a; Hualde 2002; Prieto 1998; Prieto et al. 1995, 1996; Sosa 1995, 1999). But the importance of Navarro Tomás's observations is much broader than a particular phonological theory or analysis. Even outside the scope of a particular theory of intonation, Garrido (1996, Garrido et al. 1993) recognizes that it is the F0 rise itself rather than the peak of the rise that is important in marking a syllable as stressed. While the F0 peak is generally realized on a post-tonic syllable in the body of the F0 contour, this is not the case for the final stressed syllable of a Spanish declarative. In quantitative studies, Llisterri et al. (1995) find that the F0 peak occurs on the final stressed syllable over $95 \%$ of the time, and Face (1999) finds that this is the case over $98 \%$ of the time. This difference between non-final (i.e. prenuclear) and final (i.e. nuclear) F0 rises has led to a debate as to whether the difference is phonological or only phonetic (e.g. Face 1999, 2001b, 2002a; Hualde 2002; Nibert 2000; Prieto 1998; Prieto et al. 1995, 1996; Sosa 1999). But what is important for the purposes of the present study is that there is a difference between the F0 rise in prenuclear and nuclear positions, regardless of the phonological analysis. An example pitch track demonstrating the F0 peak alignment in prenuclear and nuclear positions is given in Figure 1. 


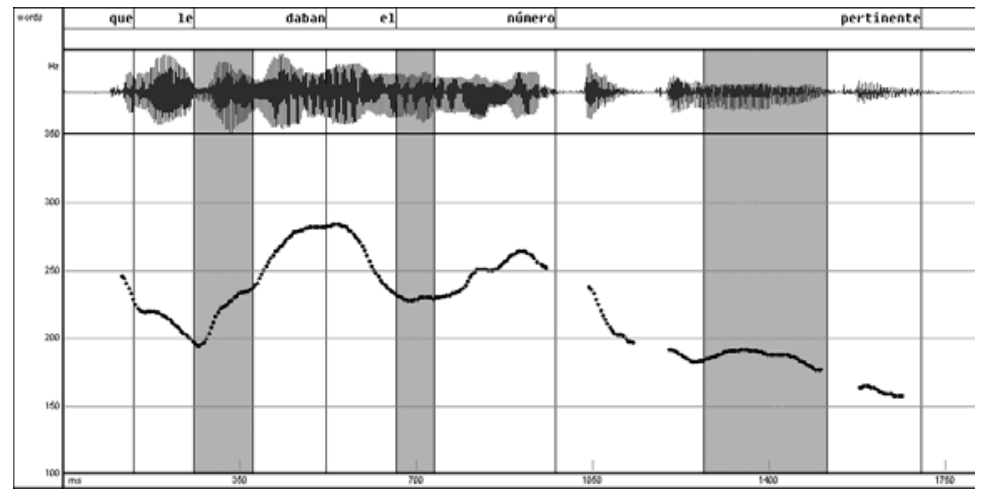

Figure 1. Intonation of a declarative utterance. Text: Que le daban el número pertinente ('That they were giving him the relevant number').

In this figure, where the stressed syllables are shaded, it can be seen that the F0 begins to rise at or near the beginning of each stressed syllable. In the case of the two pre-nuclear F0 rises, the rise ends in a post-tonic syllable, while in the case of the nuclear F0 rise, the rise ends within the tonic syllable.

Another well-studied characteristic of the intonation of Spanish declaratives, especially by Prieto et al. $(1995,1996)$, is that of downstep, a process by which each successive F0 peak is lower than the preceding peak. This can also be seen in Figure 1, where the first F0 peak is $283 \mathrm{~Hz}$, the second is $265 \mathrm{~Hz}$, and the third is 193 Hz. Prieto et al. (1996) and Face (2002a) also present evidence for a process of final lowering, which causes the height of the final F0 peak of an utterance to be lower than can be accounted for by downstepping. In some cases final lowering causes such an effect that the F0 peak becomes immeasurable (i.e. there is no visible rise in F0 in the pitch track). In the case of Figure 1, there is a visible rise in F0 in the final stressed syllable, but final lowering explains why it is so much lower than the preceding peak. Note that the drop between the first and second F0 peaks is $18 \mathrm{~Hz}$, while the drop between the second and third (i.e. last) F0 peaks is $72 \mathrm{~Hz}$.

\section{Spontaneous speech data in the present study}

The discussion in this paper of the intonation of declaratives in spontaneous Spanish is based on approximately 150 declarative utterances extracted from the Corpus de Referencia de la Lengua Española Contemporánea, Corpus Oral Centropeninsular (Marcos Marín 1994). ${ }^{1}$ The corpus contains spontaneous speech de Madrid, under the direction of Dr. Francisco Marcos Marín, with the support of IBM-Spain, 
of various types and from various sources, and represents what was perceived by the researchers collecting the corpus as «standard» Castilian Spanish. The declarative utterances examined in the present study all come from interviews of different types (e.g. radio call-in show, radio or television interview of a special guest, teacher interviewing students). All of the declarative utterances examined for the purposes of the present study were produced by the interviewee rather than by the interviewer. In this way any scripting or broadcasting style is avoided.

\section{Intonational differences between lab speech and spontaneous speech}

\subsection{The length and complexity of utterances}

While a difference in the length and complexity of utterances may not be an intonational difference in and of itself, it is nonetheless a factor that has a large impact on the intonational differences found between lab speech and spontaneous speech. In most studies which elicit lab speech, the utterances elicited are rather short and simple in structure. One example is the utterance from Figure 1, which contains only three words with stressed syllables and structurally consists of only a verb and a short object noun phrase. Another very similar typical phrase of this type is the now famous Le dieron el número de vuelo ('They gave him the flight number') employed by Sosa (1999) to compare regional intonation patterns. While longer utterances are occasionally elicited in studies of the intonation of lab speech, they are still relatively short and simple in structure. De la Mota (1997) elicits utterances such as La niña de Vigo barre la nave gallega ('The girl from Vigo sweeps the Galician ship'), and Face (2002a) elicits others such as El hermano de Manolo le daba el número de vuelo ('Manolo's brother was living him the flight number'). But in both of these cases there are only five words with a stressed syllable, and the structures are still rather simple. This is in stark contrast to what is found in spontaneous speech.

Of course there are short and structurally simple utterances found in spontaneous speech, such as the utterances Lo importante es amarse ('The important thing is to love one another') and Yo he sido muy feliz con ellos ('I have been very happy with them'), which are among the declaratives from the corpus examined for the present study. But these short and simple utterances are a minority of the utterances found in spontaneous speech, which often seem to ramble on, have numerous embedded clauses, and sometimes even defy syntactic rules.

The reason that these differences in utterance length and complexity affect intonation is largely one of phrasing. In short utterances elicited in a laboratory or other experimental setting, the phrases are generally short enough to be uttered in a single phrase. But the longer the sentence and the more syntactic boundaries, the more likely it is that the utterance will be divided into multiple phrases. While many of

between 1990 and 1993 . The corpus was provided by the aforementioned laboratory at no cost other than those associated with the process of converting the original analog recordings to a digital format and those related to the preparation and shipping of the digitized recordings. 


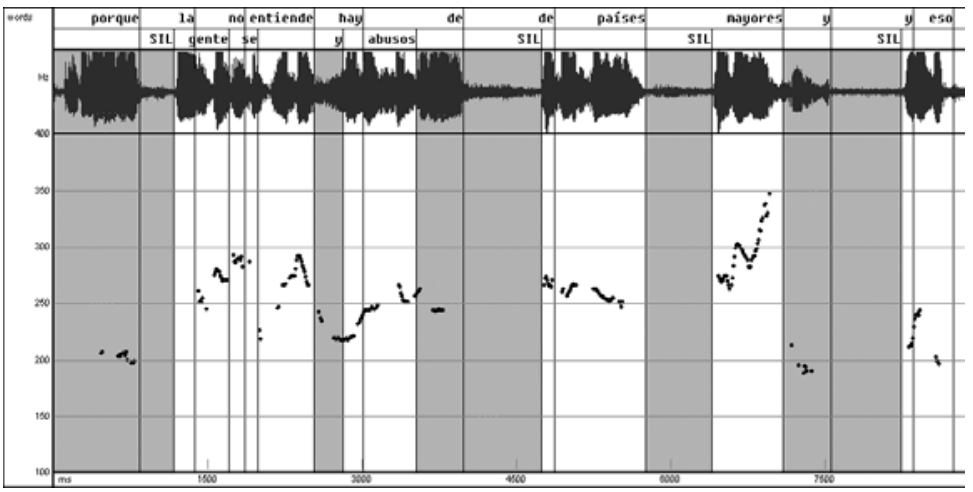

Figure 2. Declarative utterance from spontaneous speech, divided into phrases by silences and lengthening due to hesitation. Text: Porque la gente no se entiende y hay abuso de países mayores y eso ('Because people don't understand each other and there is abuse by larger countries and such').

these phrases may be clearly intentional divisions of the larger utterance (e.g. separation of old information from new), in spontaneous speech there are other factors which lead to the further division of the utterance. These are often in the form of disfluencies of one form or another. Examples are silences, hesitations and filler words while the speaker is thinking, bodily noises outside of the speech stream (e.g. a cough or sneeze or just the smacking of the lips), stopping mid-word to correct oneself, etc. All of these lead to the utterance being divided into various phrases, whether the result of linguistic intent or not. Figure 2 shows a pitch track of a declarative utterance from spontaneous speech where various sections of the utterance are clearly delimited by silences and lengthening due to hesitation.

The shaded areas in the figure mark the silences and hesitation lengthenings that divide this one sentence into various phrases. There are four silences while the speaker pauses. In addition, preceding three of the four pauses, there is a clear lengthening of the end of the preceding word as the speaker is hesitating and thinking. Also, there is a hesitation lengthening of the first use of the word $y$ even though there is no following silence. In fact, it is nearly twice as long as the final use of this word, which also is not followed by a pause. This is simply a filler word to give the speaker time to think and formulate the upcoming portion of the utterance. This type of phrasing, which may indeed be essential when «thinking on the fly» in spontaneous speech, but which seems to be extra-linguistic, is common in spontaneous speech and clearly has an effect on intonation that is not present in lab speech.

\subsection{F0 rises through stressed syllables}

As mentioned in Section 2, one of the earliest observations about Spanish intonation was that F0 rises throughout stressed syllables. This was noted by Navarro 
Tomás (1944) and has been noted by nearly all scholars of Spanish intonation since. The importance of the association between stress and a rising F0 goes beyond intonational studies, however. Many scholars have examined the acoustic correlates of Spanish stress, and it has traditionally been assumed that intensity, pitch (i.e. F0), and duration play a role in marking Spanish stress. Older work on Spanish frequently claimed that stress is marked primarily through the stressed syllable being produced with a higher intensity than the other syllables of the word (e.g. Navarro Tomás 1964). While more recent studies have shown that intensity, pitch, and duration all play a role in the acoustic marking of Spanish stress, both production studies (e.g. Quilis 1971, 1993) and perception studies (e.g. Enríquez et al. 1989) have found that pitch is the most important acoustic correlate of Spanish stress. Duration is the second most important acoustic correlate, and intensity plays a minimal role in the acoustic marking of stress. The high importance of pitch in marking Spanish stress seems to indicate that stressed syllables should not occur without a corresponding rise in F0. And this is exactly what Cruttenden (1993) finds in a study on deaccenting of old information. While old information is often deaccented (i.e. not accompanied by a pitch accent) in many languages, Cruttenden finds that Spanish accents this information just as it does new information.

While the relationship between stress and a rising F0 in Spanish may explain Cruttenden's findings, there are a few limited cases in lab speech where a stressed syllable is not accompanied by an F0 rise. In most cases where there is no visible F0 rise in pitch tracks, the lack of rise is attributed to a process reducing the pitch range to an extreme. This is true in the most extreme cases of final lowering (see Section 2) as well as in post-focal portions of an utterance containing a word in contrastive focus (de la Mota 1995, 1997; Face 2001a, 2002a). In these cases it is assumed that a rising pitch accent is present phonologically, but that the corresponding rise in F0 is overridden by a process which lowers the F0. However, Hualde (2002) provides a pitch track of the utterance Le dieron el número de vuelo ('They gave him the flight number'), in which the word número is not accompanied by an F0 rise. Hualde produced this example as an introspection of his own native intonation patterns, thinking of a context in which such a pattern would be used. This seems to indicate that deaccenting is possible in Spanish, though it is evident that in lab speech (nearly) all stressed syllables are indeed accompanied by a rising pitch accent. A question that could be asked is how frequent deaccenting is in other speech styles.

In spontaneous speech it is quite common to encounter stressed syllables that are not accompanied by a rise in F0. While a Spanish utterance may contain more pitch accents than an utterance of identical length in English, for example, it is not uncommon to find individual words or even a sequence of words unaccented. An example is seen in Figure 3.

There is a rise in $\mathrm{F} 0$ on the word más, and again on the word juntos. But on the intervening verbs vale and estar, both of which have stressed syllables, there is no rise in F0. Rather the F0 falls from the peak just after más to the beginning of juntos where the F0 begins to rise again. Also, the word separados and the final 


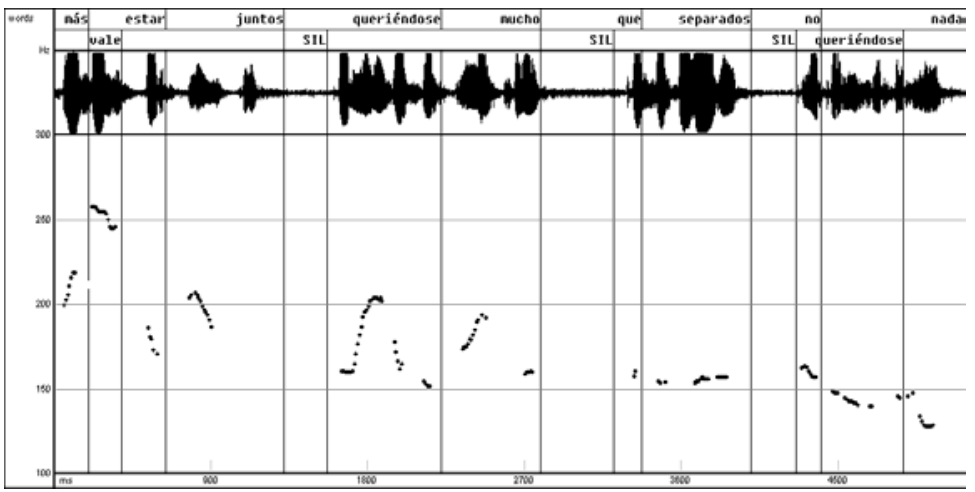

Figure 3. Utterance from spontaneous speech with various unaccented words. Text: Más vale estar juntos, queriéndose mucho, que separados, no queriéndose nada ('It is better to be together, loving each other a lot, than apart, not loving each other at all').

instance of the word queriéndose show no rise in F0. In the case of queriéndose, this is similar to the case of vale estar, in that the unaccented word is between two other accents. But in the case of separados, this is the only word containing a stressed syllable in the phrase set off by the preceding and following pauses. Whether this can be considered a phrase of its own phonologically is not addressed here. What is clear, however, is that Spanish can indeed have an unaccented word, even when that word contains a stressed syllable. A question that may be asked is how frequent such unaccented words are. A quantitative investigation of the utterances examined in the present study reveals that of all accentable words in pre-nuclear position, approximately $70 \%$ are accented. This means that approximately $30 \%$ of accentable words lack a pitch accent. While this indicates that unaccented words are not that uncommon in Spanish spontaneous speech it is also worth noting that certain categories of words are much more likely than others to lack an accent. The categories that make up the majority of unaccented words in the present study are verbs, adverbs, and what can be classified syntactically as determiners. While all verbs seem to be more susceptible to lacking an accent than do other words, this is especially true of forms of ser, estar, and haber. The syntactic determiners that are often are unaccented are words such as possessive adjectives, demonstrative adjectives, indefinite articles (which are accentable, in contrast to definite articles; cf. Hualde 1999), pre-nominal adjectives, etc. While other words may be unaccented, the aforementioned categories make up a vast majority of the unaccented words in the present study. The existence of unaccented words is something that has not generally been recognized for Spanish, but this is likely due to the fact that it appears to be a characteristic of spontaneous speech but not of lab speech, with the latter being the target of most previous investigations of Spanish intonation. 


\subsection{F0 peak alignment}

Differences in F0 peak alignment and phonological analyses of these differences have received much attention in recent studies of Spanish intonation. As discussed in Section 2, the peak at the end of an F0 rise typically occurs in a post-tonic syllable in prenuclear position and in the tonic syllable in nuclear position. Several recent studies examining lab speech have shown, however, that there are cases where the F0 peak in prenuclear position is also realized within the tonic syllable. This has been found primarily in cases of focus (Cabrera Abreu and García Lecumberri this volume; Face 2001b, 2002a, 2002b; Hualde 2002; Nibert 2000), but also in imperatives (Willis 2002). Face (2002a, 2002b) demonstrates that there are multiple strategies that Spanish speakers may use to mark a word in focus through intonation, but an early F0 peak is the most common strategy found.

One clear difference between lab speech and spontaneous speech is the respective ease or difficulty in determining what is the focus of an utterance. In studies of lab speech, a context can be created that makes clear that a particular word in an utterance is new information or is being contrasted with something else. Examples of such contexts are given in (1), where capitals indicate the word in focus.

\section{(1) Contexts to create focus}

a. New information

Who went to the store?

MARY went to the store.

b. Contrast

Did John go to the store?

MARY went to the store.

In these examples, there can be no doubt as to the status of Mary as the focus of the answer to the question. The use of such contexts in studies of focal intonation in lab speech is by no means invalid. This type of experiment certainly allows the context to be controlled in order to determine the effect on the intonation of the utterance as compared to cases where the utterance occurs in a non-focal context. But can the conclusions drawn in studies of this type be extended to spontaneous speech?

Ocampo (2002) argues that in spontaneous speech it is often impossible to determine what is the focus of an utterance by traditional definitions. Rather, the speaker often appears to subjectively determine what is important, regardless of whether it is new information, contrasts with anything else in the discourse, etc. In the spontaneous speech declarative utterances considered in the present study, nearly $25 \%$ of prenuclear F0 peaks occur within the stressed syllable in prenuclear position. Yet in many cases the word containing this tonic F0 peak does not seem to be the focus of the utterance based on the context in which the utterance occurs. This finding is seems to lend prosodic support to the finding of Ocampo (2002). Examples are shown in Figure 4 and Figure 5. 


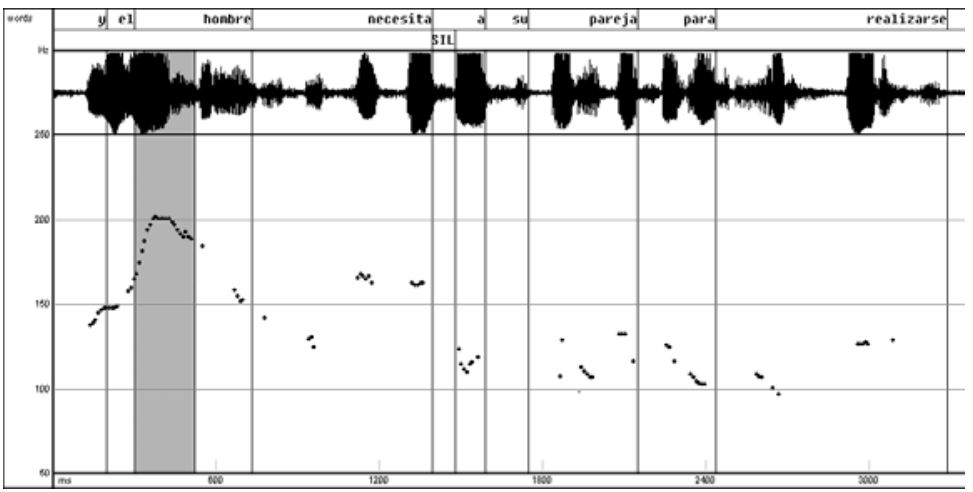

Figure 4. Utterance from spontaneous speech with F0 peak in tonic syllable in prenuclear position. Text: $Y$ el hombre necesita a su pareja para realizarse ('And man needs his mate in order to be complete').

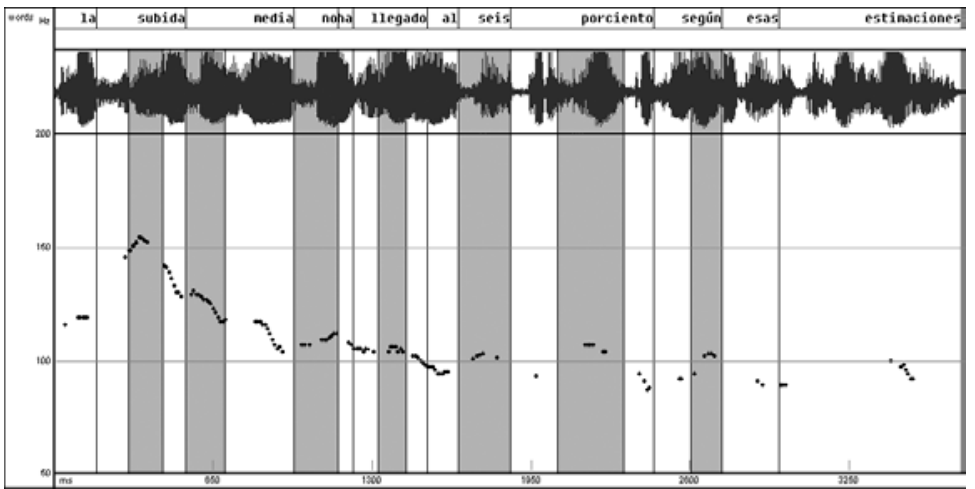

Figure 5. Utterance from spontaneous speech with F0 peaks in tonic syllables in prenuclear position. Text: La subida media no ha llegado al seis porciento según esas estimaciones ('The average increase has not reached six percent according to those estimates').

In Figure 4, there is a tonic F0 peak on the word hombre. This utterance takes place in the middle of a speaking turn by this speaker, and in the context of the discussion, hombre is neither new information (the discussion deals with marriage and the need for mates) nor contrasts with anything else, such as woman, in the discussion. Yet the F0 peak is realized in the tonic syllable. Figure 5 has various tonic F0 peaks in prenuclear position. Clearly it cannot be said that each and every one of these instances is due to focus. But the utterance does sound quite staccato, with a sense of insistence.

Obviously the contexts in which spontaneous speech occur are more complex than the fabricated contexts used in studies of lab speech. But also, each speaker 
communicates certain attitudes, emphasizes certain points, etc. So while studies of lab speech may give us some indication as to when a tonic F0 peak is used in prenuclear position (e.g. focus, imperatives), in spontaneous speech it appears that there are other cases as well. Likely focus and imperatives are the tip of an iceberg of pragmatic factors that lead to tonic F0 peaks. Highlighting a change of subject (although slight) could be the reason for the tonic F0 peak in Figure 4. Another could be a signaling of the speaker's attitude on the topic. And insistence or emphasis of the utterance could be the reason for the multiple tonic F0 peaks in Figure 5 , although this is clearly a subjective and attitudinal determination on the part of the speaker. What is clear is that (a) in spontaneous speech there is more to the story than what has been discovered in studies of lab speech, and (b) the clear-cut definitions of when a tonic F0 peak is used do not hold up.

\subsection{Downstep and final lowering}

Also discussed in Section 2 were the pitch range effects of downstep and final lowering. Both of these are very common and consistent in lab speech. They are found in any study that looks at the intonation of lab speech in Spanish, and they are so regular that Prieto et al. (1996) develop an algorithm that quite accurately models the height of F0 peaks in their data. Both downstep and final lowering have been viewed as characteristic of Spanish intonation. A look at the intonation of declaratives in spontaneous speech, however, shows that they are not as common here as they are in lab speech.

In spontaneous speech, downstep is still common, though not as automatic as one might expect based on its presence in lab speech. It is not always as clear as in lab speech due to the fact that in spontaneous speech utterances are more often divided into smaller chunks, either as a result of linguistic phrasing or due to extralinguistic reasons (see Section 4.1). This means that there may only be one or two F0 peaks within any given phrase. But within shorter phrases with multiple F0 peaks, or when a longer phrase occurs, downstepping does occur very commonly even in spontaneous speech. An example is shown in Figure 6.

In this utterance there are three phrases delimited intonationally. The second phrase, que los niños aprendan lo que es una... una ciudad moderna ('that the children learn what is a.... modern city'), shows an extended stretch of speech where downstepping can be seen. Each F0 rise in this phrase reaches a peak that is lower than the preceding F0 peak.

But there are also cases in spontaneous speech when there is not downstepping. In fact in slightly more than half of the cases considered in the present study, no downstepping is present. In the remaining cases, downstepping is most often present in only a portion of the utterance. At this point it is not clear what the pragmatic difference is between the production of a sentence or phrase with downstepping and its production without downstepping. This is an important issue that will need to be addressed in future studies. For the time being what can be said is that in spontaneous speech there are cases where downstepping does not occur in declarative utterances. An example is given in Figure 7. 


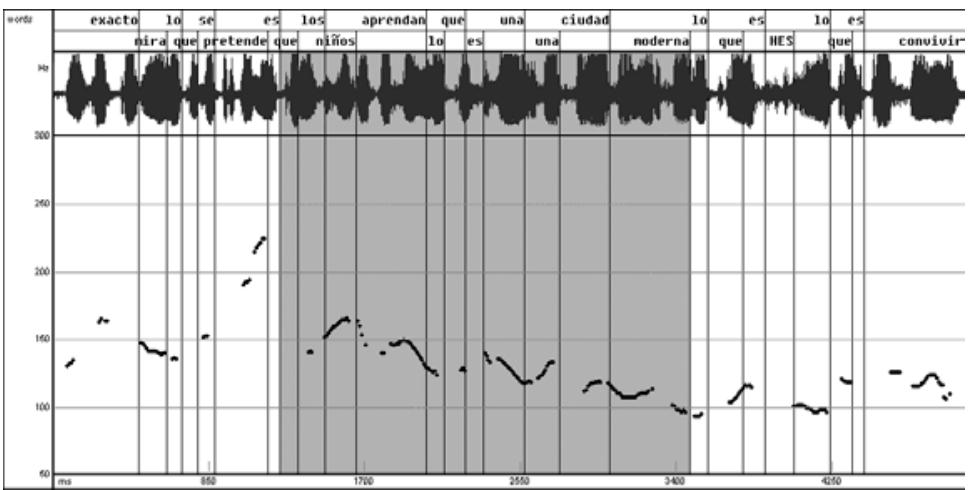

Figure 6. Utterance from spontaneous speech showing downstepping. Text: Exacto. Mira, lo que se pretende es que los niños aprendan lo que es una... una ciudad moderna, lo que es...lo que es convivir ('Exactly. Look, the goal is for children to learn what is a... a modern city, what it is... what it is to live together').

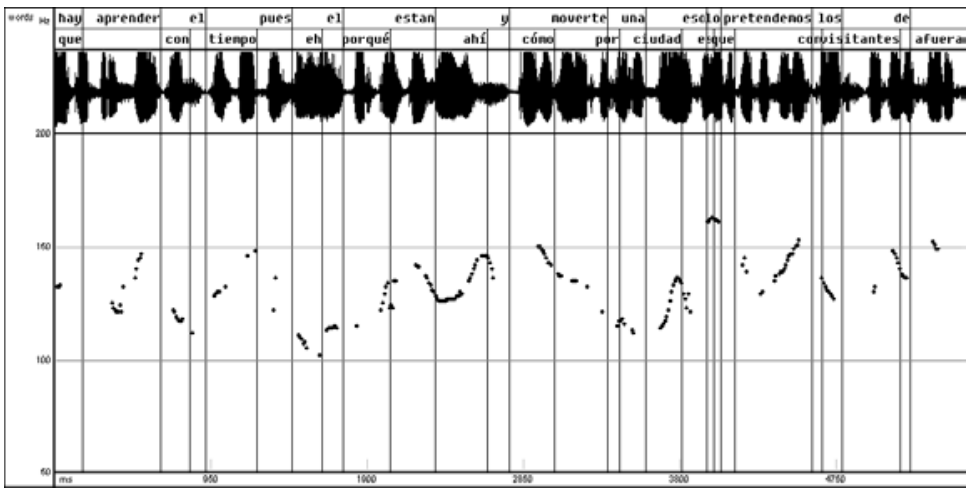

Figure 7. Utterance from spontaneous speech lacking downstepping. Text: Hay que aprender con el tiempo pues, eh, el porqué están ahí y cómo moverte por una ciudad; eso es lo que pretendemos con los visitantes de afuera ('One must learn with time then, uh, why they are there and how to move about a city; this is what we try to accomplish with visitors from outside').

In this figure, although there are phrases with multiple F0 peaks, it can be seen that there is no downstepping pattern such as that seen in Figure 6.

Like downstepping, final lowering occurs in spontaneous speech as it does in lab speech. However, while downstepping is fairly common in spontaneous speech, final lowering is not. When final lowering does occur in spontaneous speech, the information on which the reduced F0 rise (or lack of F0 rise) occurs is typically repeated information or information which is predictable based on the context. An example is shown in Figure 8. 


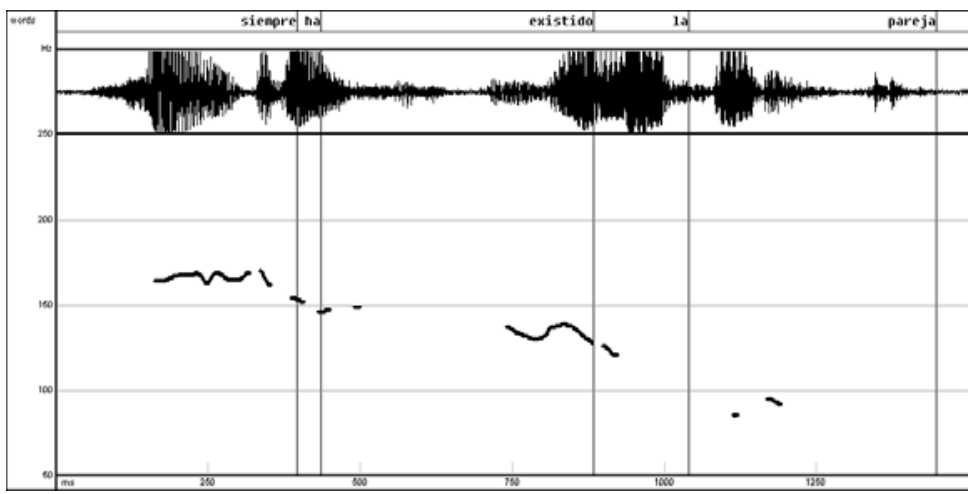

Figure 8. Utterance from spontaneous speech showing final lowering. Text: Siempre ha existido la pareja ('The couple has always existed').

In this figure the final F0 peak of the sentence has a much lower F0 value than the preceding peaks. The word pareja has the lower F0 peak on it, and is a word that is predictable based on the preceding context. The speaker of this utterance, prior to this particular utterance, has been advocating couples and the necessity of couples rather than individuals living alone. Therefore while what is being said about couples in this utterance may be new information in the discourse, the fact that it is related to couples is predictable. For this reason the F0 peak on the word pareja demonstrates final lowering.

While final lowering does occur in spontaneous speech, it is much more common to find a prominent $\mathrm{F} 0$ rise on the final word of an utterance. In many cases the final F0 rise is notably higher than the preceding F0 rise. In fact this higher final F0 rise outnumbers cases of final lowering by nearly a three-to-one margin. An example of a higher final F0 rise is given in Figure 9.

In this figure the final F0 peak is higher than all other F0 peaks in the utterance except the first two. There appears to be a downstepping pattern, though not as prominent as in some cases, through the majority of the utterance. But upon reaching the final word, there is neither downstep nor final lowering. Rather the F0 peak on this word is very high and prominent. This is quite common in spontaneous speech, and seems to indicate the importance of the final word, in contrast to cases of final lowering when the final word is repeated or predictable information. This goes along nicely with studies of Spanish word order (e.g. Bolinger 1954, 1954-1955; Contreras 1978, 1980), which have traditionally claimed special prominence for final position in the utterance. What is not clear, however, is why this higher F0 peak found so often in spontaneous speech is not found in lab speech. I would suggest that this is likely due to lab speech being scripted and the speaker simply reading the script provided by the researcher. In spontaneous speech the speaker is under the influence of all of the factors of context, emotion, and the like that can affect pragmatic meaning, and this is reflected in the intonation patterns used. 


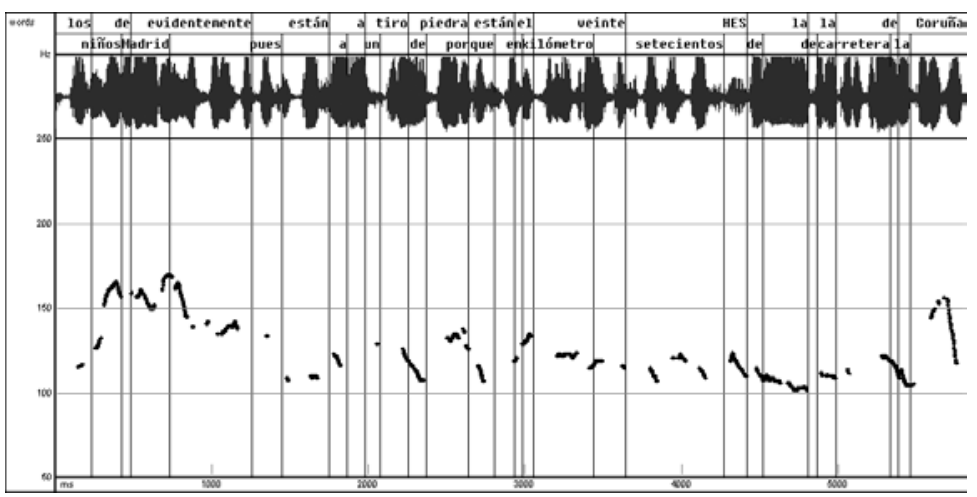

Figure 9. Utterance from spontaneous speech without final lowering. Text: Los niños de Madrid evidentemente, pues, están a a un tiro de piedra porque están en el kilómetro veinte setecientos de la de la carretera de La Coruña ('The children from Madrid evidently, then, are at at a stone's throw away because they are at 20 kilometers and 700 meters from the from the La Coruña highway').

\section{Conclusion}

Nearly all previous studies of Spanish intonation have examined lab speech. The present study takes a step toward determining how the intonation patterns of Spanish lab speech and spontaneous speech are similar and how they differ. As the present study is only a first step, it took as its point of departure the most well-studied sentences in studies of Spanish intonation: declaratives. In addition, the present study was limited to the most well-studied characteristics of the intonation of Spanish declaratives in lab speech: F0 rises in stressed syllables, F0 peak alignment, downstepping, and final lowering.

As in lab speech, F0 generally rises through stressed syllables in spontaneous speech. However, while stressed syllables almost without fail are accompanied by an F0 rise in lab speech, in spontaneous speech it is not uncommon to find words or even strings of words with no F0 rises in their stressed syllables. It stands to reason that F0 rises accompany words of higher communicative importance and not those of lesser importance. This is common across languages, and perhaps Spanish is no different in this sense. Future studies will need to examine carefully what factors affect a speaker's decision to accent a word with an F0 rise or leave it unaccented.

Studies of Spanish F0 peak alignment are numerous. But they examine clearcut categories such as broad focus declaratives, contrastive focus, and imperatives. As was discussed in Section 4.3, these types of categories can be clearly identified through carefully constructed contexts in studies of lab speech. In spontaneous speech, identifying such categories is much more difficult. Still, there seem to be similarities between lab speech and spontaneous speech. In lab speech, the normal 
F0 peak alignment is for the peak to occur in a post-tonic syllable. It occurs within the tonic syllable in cases of focus or in an imperative verb. In spontaneous speech, F0 peaks within the tonic syllable seem to indicate emphatic speech, although the pragmatic factors which can lead to this vaguely termed «emphatic» intonation will require much future study.

Downstepping is a very consistent characteristic of the intonation of Spanish lab speech, and it is very common in spontaneous speech as well. In some cases, however, a lack of downstepping is found in declaratives in spontaneous speech. At this point it is not clear what the pragmatic difference is between downstepping and lack of downstepping. This is yet another of the various issues related to the meaning of intonation patterns that must be examined in future research.

Final lowering, while very common in lab speech, is not very common in spontaneous speech, though it does exist. Where it is used in spontaneous speech, it marks repeated or predictable information. When the information communicated by the final word of the utterance is not repeated or predictable information, final lowering is not used. In fact, in these cases it is very common for the final F0 peak to be higher than the preceding F0 peaks, lending prominence to the word on which this F0 peak is used.

The present study takes a step forward in the study of Spanish intonation by examining certain aspects of the intonation of spontaneous Spanish declaratives. But perhaps more important are the questions that the present study leaves unanswered. Most of these relate to the meaning of intonational characteristics found in Spanish speech. Much work is needed on the relationship between intonation and pragmatic meaning. Another area not addressed in the present study, but which must be addressed in future studies, is that of a phonological analysis of the intonation patterns found in spontaneous speech. This is also related to pragmatic meaning, as differences in meaning, or lack thereof, will be important in determining whether phonetically similar, but not identical, intonation patterns merit an analysis in which they are phonologically distinct or not. These are the most important issues left unaddressed in the present study, but certainly there are many more issues to be investigated on the intonation of spontaneous Spanish as well. It is my hope that the present study spurs further research in this wide-open field of study.

\section{References}

Bolinger, Dwight L. (1954). «English prosodic stress and Spanish sentence order». Hispania 37: 152-156.

- (1954-1955). «Meaningful word order in Spanish». Boletín de Filología 8: 45-56.

Cabrera Abreu, Mercedes; García Lecumberri, María Luisa (this volume). «The manifestation of intonational focus in Castilian Spanish».

Contreras, Heles (1978). El orden de palabras en español. Madrid: Cátedra.

- (1980). «Sentential stress, word order and the notion of subject in Spanish». In: Waugh, Linda R.; van Schooneveld, C.H. (eds.). The melody of language. Baltimore: University Park Press, pp. 45-53. 
de la Mota, Carme (1995). La representación gramatical de la información nueva en el discurso. Universitat Autònoma de Barcelona, doctoral dissertation.

- (1997). «Prosody of sentences with contrastive new information in Spanish». In: Botinis, Antonis et al. (eds.). Intonation: Theory, Models and ApplicationsProceedings of an ESCA Workshop. Athens: ESCA/University of Athens, pp. 75-78.

Enríquez, Emilia V.; Casado, Celia; Santos, Andrés (1989). «La percepción del acento en español». Lingüística Española Actual 11: 241-269.

Face, Timothy L. (1999). «A phonological analysis of rising pitch in Castilian Spanish». Hispanic Linguistics 11.

- (2001a). «Contrastive focus and global intonation patterns in Spanish». Linguistic Association of Korea Journal 9.2: 1-21.

- (2001b). «Focus and early peak alignment in Spanish intonation». Probus 13: 223-246.

- (2002a). Intonational marking of contrastive focus in Madrid Spanish. Munich: Lincom Europa.

- (2002b). «Local intonational marking of Spanish contrastive focus». Probus 14: 71-92.

Farrar, Kimberley; Grabe, Esther; Nolan, Francis (1999).«English intonation in the British isles». Leeds Studies in English 29: 243-256.

Garrido, Juan M (1996). Modelling Spanish intonation for text-to-speech applications. Universitat Autònoma de Barcelona, doctoral dissertation.

Garrido, Juan M; Llisterri, Joaquim; de la Mota, Carme; Ríos, Antonio (1993). «Prosodic differences in reading style: Isolated vs. contextualized sentences». Proceedings of Eurospeech '93, pp. 573-576.

Grabe, Esther (1998). Comparative intonational phonology: English and German. Nijmegen: Max Planck Institute.

Hualde, José Ignacio (1999). «Basic intonational contours in Spanish». Presentation at the First ToBI Workshop, Columbus, Ohio, 1-3 October.

- (2002). «Intonation in Spanish and the other Ibero-Romance languages». In: Wiltshire, Caroline; Camps, Joaquim (eds.). Romance Phonology and Variation, Philadelphia: John Benjamins, pp. 101-115.

Krahmer, Emiel; Swertz, Marc (2001). «On the alleged existence of contrastive accents». Speech Communication 34: 391-405.

Llisterri, Joaquim; Marín, Rafael; de la Mota, Carme; Ríos, Antonio (1995). «Factors affecting F0 peak displacement in Spanish». EUROSPEECH '95, pp. 2061-2064.

Marcos Marín, Francisco (1994). Informática y humanidades. Madrid: Gredos.

Navarro Tomás, Tomás (1918). Manual de pronunciación española. Madrid: Centro de Estudios Históricos.

- (1944). Manual de entonación española. New York: Hispanic Institute in the United States.

Nibert, Holly J. (2000). Phonetic and phonological evidence for intermediate phrasing in Spanish intonation. University of Illinois at Urbana-Champaign, doctoral dissertation.

Ocampo, Francisco (2002). On the notion of focus in spoken Spanish: An empirical approach. Manuscript, University of Minnesota. 
Prieto, Pilar; Nibert, Holly; Shih, Chilin (1995). «The absence or presence of a declination effect on the descent of F0 peaks? Evidence from Mexican Spanish». In: Zagona, Karen (ed.). Grammatical Theory and Romance Languages. Philadelphia: John Benjamins, pp. 197-207.

Prieto, Pilar; Shih, Chilin (1995). «Effects of tonal clash on downstepped $\mathrm{H}^{*}$ accents in Spanish». EUROSPEECH '95, pp. 1307-1310.

Prieto, Pilar; Shih, Chilin; Nibert, Holly (1996). «Pitch downtrend in Spanish». Journal of Phonetics 24: 445-473.

Prieto, Pilar (1998). «The scaling of the $\mathrm{L}$ values in Spanish downstepping contours». Journal of Phonetics 26: 261-282.

Quilis, Antonio (1971). «Caracterización fonética del acento español». Travaux de Linguistique et de Litérature 9: 53-72.

Sosa, Juan Manuel (1995). «Nuclear and pre-nuclear tonal inventories and the phonology of Spanish declarative intonation». Proceedings of the International Congress of Phonetic Sciences '95 13.4: 646-649.

- (1999). La entonación del español. Madrid: Cátedra. 